\title{
Sport and Ethics of Weak Thought: A New Manifesto for Sport Education
}

\section{Authors' contribution:}

A) conception and design of the study

B) acquisition of data

C) analysis and interpretation of data

D) manuscript preparation

E) obtaining funding

\author{
Emanuele Isidori ${ }^{1 \mathrm{~A}, \mathrm{E}}$, Claudia Maulini ${ }^{1 \mathrm{~B}, \mathrm{C}}$, \\ Francisco Javier López Frías ${ }^{2}$ C,D \\ ${ }^{1}$ Foro Italico, University of Rome, Italy \\ ${ }^{2}$ University of Valencia, Spain
}

ABSTRACT

The so-called "weak thought", theorized by the Italian postmodernist philosopher Gianni Vattimo (born in 1936), considered one of the most important Italian philosophers, has dismantled the main concepts on which Western philosophy was based (that is, the notion of Truth, God, Reason, an absolute foundation to thought, etc.). This philosophy, which is inspired by Nietzsche's nihilism, by Heidegger, and by the philosophy of hermeneutics and deconstruction, offers a critical starting point not only to rethink, in a less rigid way, our Western culture, its philosophy, and its problems, but also the ethical principles and educational values that guide human life.

Sport - as a human phenomenon and philosophical problem characterized by the presence of values, norms, behaviors, and rules that involves the action of human beings who interact and communicate "in" and "by" the game - can also be read in the light of this emerging philosophical theory.

The aim of this study is to demonstrate that weak thought and its fundamental categories can be used and applied from a theoretical point of view in order to interpret and understand sport, deconstructing its meanings and its sociocultural and educational values.

Using the critical contribution of weak thought, in this study we will reflect on and rethink in a new way some of the main concepts considered absolute and fundamental to sport's logical and philosophical structure, such as "winning" and "losing", "referee" (which embodies the principle of "authority"), "opponent", "freedom" in the game, "rules", and respect when one plays.

The purpose of this study is to undertake a critical reflection on the limits of the concept of sport proposed by the Western tradition and to lay the foundations for a new model of ethics and education for the sports of the future.

KEYWORDS education, hermeneutics, pedagogy, sport, Weak Thought

\section{Introduction}

In this article, we will proceed as follows. First of all, we will define briefly what weak thought is by briefly trying to reconstruct its philosophical, historical, and cultural matrix. We need this short introduction because weak thought has never been applied to sport and its philosophical problems. Second, we will show the possible applications of the principles of weak thought to sport by pointing out the consequences of this 
potential application to sports education. The purpose of this article is to begin a critical reflection on the limits of the concept of sport as conceived in the framework of the Western tradition, thereby revealing the possibility of a new model for sport ethics.

\section{What is Weak Thought?}

Gianni Vattimo (1936), professor emeritus at the University of Turin, and Pier Aldo Rovatti (1942), professor at the University of Trieste, are the two Italian professors who coined the term "weak thought" pensiero debole in Italian - in the 1970s. They are two of the most important theorists of postmodern philosophy in Europe and in the world. However, weak thought is not just a philosophical and ethical critique on modernity. Rather, weak thought also criticizes postmodernism.

Weak thought's starting point is the nihilist situation in which we are. At the beginning of the twentieth century, our conception of the world and of philosophy experienced a new change: the dismantling of the main concepts upon which they were based (i.e., the notion of Truth, God, Reason, an absolute foundation to thought, etc.), which means the dismantling of Western society (Vattimo, 1994). Friedrich Nietzsche and Martin Heidegger induced this change by criticizing the modern roots of philosophy and society. In so DOIng, they became the founders of postmodern philosophy. Weak thought is thus presented as a particular form of postmodernism influenced by those philosophers who initiated an irreversible crisis within the foundation of rationalistic and Cartesian way of thinking and DOIng philosophy.

Weak thought discusses and distorts the paradigm developed during modernity. The critique of modernity has been a hot topic in philosophy in the twentieth century. However, weak thought differentiates itself from other postmodernist proposals that emerged around the 1970s - it is not a negative nihilism as the one defended by most of the French postmodern philosophers. Thus, weak thought is also a reaction against "strong antimodern thought". Vattimo strongly criticizes both Marxism and those Marxist-inspired authors, like Foucault, Derrida, and Deleuze, who embraced Marx's, Heidegger's, and Nietzsche's claims against modern society. According to Vattimo's weak thought, these postmodern proposals were too extreme - too vitalistic and violent. They exaggerated the nihilist critique on modernity to such an extreme that they led to dangerous extreme positions - for instance, Vattimo argues that the people who followed those proposals were too prone to take up arms and talk about "armed struggle", "struggle of classes", and so on (D'Agostini, 2012).

In opposition to such extreme proposals, weak thought is conceived of as a weak postmodernism and a positive form of nihilism. Vattimo, as a critic of modern age, shares a set of basic critical claims, which are referred to the flaws of modernity, with other postmodernist proposals. According to this common critical point of view, the great philosophies of the modern age (derived from the tradition of Greek thought and Judeo-Christian worldviews: rationalism, empiricism, Kantianism, idealism, positivism, Marxism, historicism, and their latest contemporary developments such as pragmatism, logical positivism, analytic philosophy, critical rationalism, and structuralism) are mostly characterized by the following:

1. The subject plays a strong role in terms of both ethics and epistemological knowledge;

2. The concept of "truth" is understood as a self-evident foundation (Truth exists, there is only one Truth, and no other truths are allowed);

3. An underlying optimism about the order is defended: The intrinsic logic and (ultimate) teleology of history destined to achieve the ultimate fulfillment of its intrinsic purpose (as theorized by Hegel and his dialectics);

4. The scientific distinction (typical of historicism) between rational explanation, based on empirical evidence like in natural sciences (Erklärung), and interpretation (Verstehung), which involves communication and a intersubjective interpretation of the scientific object.

Weak thought argues that these four main assumptions are mistaken. There is not a transcendental reality (the "I" the truth, the World) to which we can appeal. The modern interpretation of the world is just one of the possible points of view on reality and humankind that human beings have proposed through their 
history. However, proponents of modernity cannot acknowledge this nihilist claim since the basis of their interpretation consists in arguing that if individual reason is applied correctly - that is to say, in a scientific way - it will be able to grasp the truer representation of the world - of the Being (D'Agostini, 2012).

As hermeneutics claims, twentieth-century philosophy is unavoidably linguistic philosophy. Philosophy focuses on practices and communitarian experiences of existing human beings and the media through which they interact: symbols, codes, protocols, habits, and traditions. All of them are linguistically constituted. Experience is then only possible through language, in language, and after language (D'Agostini, 2012). The modern claim, based on Descartes' famous sentence "I think, therefore I am", that individuals are able to experience by themselves and thereby to grasp truth in such a process of individual experience is misguided.

Linguistic philosophy induces a new Copernican turn in philosophy (Vattimo, 1985). Humankind is moved again to an uncertain place in which it is not the center of experience. According to Vattimo, as experience is linked to language, truth is built in an impure way; relationships among subjects constitute truth in a communitarian - rhetorical - way. Truth is no longer something that human beings grasp in the process of interpretation. However, it is such a process that constitutes truth.

Human beings need common interpretations to solve the enigma that is the world in which we live. As Nietzsche claims, truth becomes a human tool for survival and emancipation. Human interpretations of the world pursue this basic goal. This notion of truth grounds nihilism and places in question the rational foundation of Western society. Therefore, postmodernism, as Adorno and Horkheimer showed in their Dialectic of Enlightenment, argues that the modern purpose of emancipation through rationalizing the world is doomed to fail.

As a result of this critique on the modern idea of truth, the notion of difference becomes a key concept (Vattimo, 1993). Since our metaphysical conceptions of the world become, under the aforementioned linguistic paradigm, diverse ways of human self-assurance, postmodernism admits the possibility of relativism (fragmented, nonuniqueness, relativity of the world) and the existence of alternatives to traditional scientific methods used by natural sciences (the deconstructionist method, for example). Fragmentation, precariousness, complexity, relativity, and uncertainty prevail in history and in the world over the idea of truth as a "foundation" and a "monolith"; it is impossible to achieve an "objective" and an absolute understanding of the world and its phenomena.

These are Vattimo's postmodern and nihilist ideas. As we claimed before, weak thought proposes a positive version of nihilism. So it tries to be a third way situated in a place between antinihilist modernism and the negative nihilism of postmodernism. According to Vattimo, the postmodern and nihilist devaluation of the highest values and the death of God have brought a defense of other "truer values". If postmodernism is conceived in this way, then it is a repetition of modern metaphysics; it is still postmetaphysics. Thus, postmodernism turns into another example of the strong thought that negates the main purpose of nihilism: turning philosophy into a constant task of interrogating ourselves about who and what we are.

The main purpose of Vattimo's proposal is to find a place in between the strong proposals of modern and postmodern authors. His opposition to use strong principles to build his theory is one of the reasons why his proposal is called "weak". However, there are other reasons. For instance, there is an ethical reason; metaphysics defend the existence of a foundation whose incontrovertible evidence no longer admits further enquiry. Metaphysical knowledge becomes an authority that keeps things quiet and takes violent control of the issue without explanation (Vattimo, 1997, p. 31).

Vattimo is against such types of "violent thinking" based on truer representations of the world. $\mathrm{He}$ avoids extreme positions and aims to dissolve fundamentalisms of every kind. So, instead of recovering notions of identity, philosophy should embrace difference, change, movement, and weakness as a chance for emancipation (Vattimo, 1997, p. 40). "Weak" means "incomplete" and "pluralistic". There are many truths, texts, and interpretations, and moreover, none of them is complete or definitive. 
Although weak thought is essentially linked to pluralism, contingency, and incompleteness, Vattimo claims that it is not relativistic. Rather, he argues that weak thought has a critical consciousness. The fact that weak thought is not linked to transcendental principles, but to impure conditions does not mean that it lacks critical resources. As far as weak thought is linked to such an impure reality, it has an "empiricist" nature (D'Agostini, 2012). This impure reality can also provide critical tools to evaluate the interpretations of the world that we create.

According to Vattimo, such a reality is everyday life (D'Agostini, 2012). Weak thought links its critical consciousness to pragmatics and conventions by drawing on the primary fact of human existence: Individuals are "being-there" constituted by linguistic rules, traditions, and values, accepted for a period of time. Human beings are being-there with others, so their interactions are always mediated by indefinite horizon of possibilities.

The recognition of the existence of the infinite horizon of possibilities that mediate our interactions embraces an attitude toward the world, which is not just a theoretical attitude, but an ethical one. Such an attitude is listening to others, to the world. Thus, freedom and reciprocal respect emerge as two critical criteria that point at the way social beings should exist; political animals, using Aristotle's terms, have to know the language rules, associations, professions, disciplines, and the like, and make an effort to try to understand and talk to them. In so DOIng, "dialectics" and "difference" become the two key terms in weak thought. The relationship that Vattimo establishes between them creates a positive dialectic that is the identifying mark of weak thought (Vattimo, 1985).

Positive dialectic does not avoid talking about truth. In fact, Vattimo claims that weak thought is related to truth, but to a particular conception of truth. As mentioned before, truth is a matter of persuasion for Vattimo (D'Agostini, 2012). However, we need to appeal to some shared assumptions and to a shared situation to persuade others to accept a particular interpretation of the world. Those shared elements are grounded in the history of Being. So, although Vattimo's conception of truth defends pluralism and difference, it is also linked to a certain "logic" that is there.

As being-there in a particular situation, we inherit a particular interpretation of the world. The society in which we grow up transmits it to us. But we do not endorse it completely, we rethink it we build new interpretations over what we have inherited. This means that we should be capable of tracing lines of continuity in the history of the being by identifying those elements that remain at the bottom of our interpretations. Moreover, it looks like it is such remaining elements that provide the criteria to decide which interpretations persuade others (Vattimo, 2004).

We can grasp a certain idea of an adequation to a "logic" in Vattimo's proposal. However, such an idea does not consist in artistic praxis - or aesthetics values - that convince others. "Adequation" here consists more in "satisfying" certain conditions given in our being-there (Vattimo, 2012). Thus, certain interpretations "go better" than others with our given situation. For Vattimo, "goes better" means that a certain interpretation of the world fits with the inherited cultural messages that belong to the history of Being. Thus, the Being is something that "there is", but it is only given in history. So, although the criteria that we inherit in our situation might try to present themselves as definitive, philosophers should know that they are not. However, until somebody proves that they are mistaken, they are the criteria that we use to evaluate the "adequacy" of our interpretations of the world.

As some critiques of hermeneutic philosophy claim, weak thought might be linked to "anything goes" at some point (D'Agostini, 2012). However, Vattimo argues that it is linked to a nonrelativizable version of it. There are two reasons why this is so. First, we always inherit several criteria from the society of which we are part. Second, we can trace lines of continuity in the history of Being, so we can grasp that thing that the being is. According to Vattimo, such lines show that both emancipation and living better with others charity - are two basic criteria that have always been there in the history of Being. The ethical aspect of Vattimo's theory emerges again. Theoretical interpretation is always a practical matter. Something is 
required for our being-there. There is no clear-cut distinction between theory and praxis; they are intrinsically linked.

\section{Weak Thought as a way to rethink sport}

Weak thought develops some implications of Nietzsche's nihilism, of Heidegger's existentialism, and of the philosophy of hermeneutics and deconstruction that can provide sport philosophers with critical tools not only to rethink, in a less rigid way, Western culture and philosophy itself, but also the ethical and educational values that orient human life (Isidori, 2010). Sport - as a human phenomenon and philosophical problem characterized by the presence of values, norms, behaviors, and rules that involve the interaction of human beings - can also be read in light of this emerging philosophical theory. The question we should ask at this point is "How can we really apply the fundamental categories of weak thought to sport in order to better deconstruct its educational meanings and to expand the possibilities for human beings to be engaged in?"

The contributions that weak thought can make to the deconstruction of sport and its values fall into four main categories:

- ethical,

- epistemological,

- methodological, and

- metaphysical.

Here we will focus on levels a and d (that is, ethical and metaphysical levels). In order to do so, we will first summarize some basic concepts from weak thought that can have an impact on sport's interpretation and deconstruction. These concepts can be useful in revising our conception of sport as a cultural and social practice in the light of postmodern philosophical paradigms.

1. "Modernity (which was identified with certain values of the Enlightenment and nineteenth-century culture) is over". We live after the end of modernity, in the postmodern era (or hypermodernity, as some have claimed), which is an age, according to the French philosopher Lyotard, characterized by the end of the big Western narratives (trusting of the religions of state, churches, science, the decline of ideologies, etc.). This is the era of the "death of God" (which does not mean the death of religious feeling, but the contrary), in an era when such concepts as homeland or nation no longer make sense;

2. We must be aware that every position we take toward the world and the events that happen in its framework is always relative; we cannot accept the illusion of a single "true" point of view, the "monologue" of an individual speech. This relativist position, which is strongly criticized by the Catholic Church today (I think because of a misunderstanding), affirms that, on the one hand, in the name of the relativity of all perspectives, "there is no truth"; while on the other hand, still in the name of this relativity, one can accept the idea that a person may be persuaded that only one truth exists and still respect her or him in the name of tolerance;

3. Weak thought does not recognize any principle that is imposed by authority; it does not recognize hierarchies of power and force without any previous negotiation and agreement among individuals. At the same time, it does not accept violence, oppression, and discrimination of any kind.

We can use these principles as a means to deconstruct some traditionally unquestioned concepts related to the structure of sport:

- winning and losing,

- the authority of the referee,

- opponents,

- respect,

- freedom in play and games, and

- the nature of sports. 
Used as a hermeneutical tool, weak thought invites us to rethink the fundamental structure of sport, revealing the possibility of many cultural challenges. This rethinking of sport may involve the following points:

1. Weak thought cannot accept competitive sport engaged in by nations. We have seen how concepts such as homeland and nation, born with the birth of modern society, no longer have meaning in light of the postmodern and post-Enlightenment society in which we live. In the name of God, fatherland, and nation, men have fought and are still fighting the worst and most destructive and fratricidal wars, which have destroyed civilizations and are perpetuating aberrant crimes and violence. Therefore, why should we accept, on the one hand, the end of the so-called big narratives in the history of humankind and at the same time, on the other end, accept such an idea of sport as it is conceived in contemporary culture and society?

Why would rejecting such concepts as homeland, country, and nation have such a radical impact on contemporary sport? These are the concepts that generate the worst violence among fans who perceive themselves both as adversaries and enemies. The idea of nations, still present in contemporary sport, brings us back to the big nationalistic battles of the wars that have caused so much destruction in the history of Europe and of the world.

Weak thought wants a sport conceived without national anthems and teams identified in nations; in short, it wants a competitive spirit without opposition, because it wants a sport that recognizes the common root and original strain of humankind and stresses a concept of competition conceived not only as friendship but also as "co-opetition".

2. Weak thought also rejects a sport divided by gender, ethnicity/race, or religion. Nowadays, sport can generate dangerous speeches about race and racism (through discourse about genetic predispositions to sporting success or failure of athletes based on their membership in certain ethnic groups). Sport is a physical and cultural practice influenced by numerous cultural, educational, social, psychological, and historical factors, and the differences among ethnic groups cannot be regarded as so influential in sport and physical activity as to justify any form of discrimination. Moreover, weak thought cannot accept the concept of a weaker predisposition of women for sport and the idea that there should be separate sports for males and females, etc. It does not accept sports competitions or physical activity in which the genders are differentiated.

Because of not accepting any sex or gender discrimination, weak thought believes that sport should be practiced by integrating the genders. In the name of tolerance and respect for sexual difference, it also accepts transgenderism, transexualism, and homosexuality in sport;

3. Weak thought recognizes the diversity of cultures, of sports, and of their intrinsic cultural value (all sports are an expression of human creativity and are equal in dignity), and it uses the multicultural nature of sport as a tool and resource for inclusion;

4. Weak thought does not have a contra-(op)positive conception of sport but a confrontational one. The opponent is not an ad-versus, a person that is hostile and against me, but a con-versus, a friend, another human being with whom I converse and with whom together I aspire to a common purpose, that is playing the same play/game and respecting the same rules;

5. Weak thought assumes that the voluntary consent given by the player to the rules of the game, which is always freely negotiated, involves the possibility of an ethics of respect and self-judgment of the final results of the game. For this reason, weak thought thinks of a sport without referees, because those who play are able to judge by themselves and do not need any control outside their thinking;

6. Weak thought banishes violence in play and sport as an expression of strong categories (the winning and losing). It abhors the concept of victory as an expression of power that the weak thought sees in its real Latin root in the sense of "having the possibility and ability to" (prove their value) and not in the sense of oppression, domination, and destruction of the other;

7. Weak thought looks at the pleasure of playing as the main essence of sport. In short, the "weak sport" is a sport without a winner and a loser. This kind of thinking does not deny the concept of sport 
conceived both as play and game, or as a recreational activity characterized by the rules that can include the traditional idea of victory and defeat, but it tends to sum it up in the essence of a free play, of a creative and intrinsic satisfaction and pleasure;

8. Weak thought does not deny the religious, transcendent, or spiritual dimension of sport. Weak thought assumes that sport is a physical experience that refers to something more than a merely material and bodily experience. It sees in the religious dimension an intimate experience that every human being has as a manifestation and a gift from God and has an openness to the possibility of understanding other meanings of life. This God, to whom the sporting experience can lead, is the God that would be too reductive to define as "Christian" because it is the God of mystical experience, the God of Love (that is, a total gift of ourselves to others), the God of friendship and agape among men and women who are engaged in sports and play through their bodies and movement as an expression of their spirituality.

\section{Pedagogical implications of Weak Thought for the ehics of sport}

From what we have claimed above, we think that it emerges clearly that weak thought always has its primary focus on the ethical dimension of sport and aims to defend humankind from all the practices of alienation, commodification, oppression, and control. So we can conclude that weak thought is primarily a socioethical thought that, by using critical-deconstructive and hermeneutic methodology to decompose and recompose sport's paradoxes, ambiguities, contradictions, and aporias, aims to show the deeper structure of sport as a human practice.

At this point, a question to be posed is "Can weak thought lead us to imagine sport as 'weak' because it is characterized by an active nihilism and, at the same time, as 'strong' in terms of its critical and transformative power?" We believe that sport should now reconsider some of its founding assumptions (those mentioned at the beginning of this paper) because it is one of the last big narratives of modernity that must be rethought in light of the changes of thought that happened in the postmodern and complex society.

The idea of a "weak sport" thought in the way of the weak thought seems to be a utopia, due to the interests, ideologies, prejudices, and beliefs that so strongly characterize sport in contemporary society. But it is precisely this utopian character of weak thought that gives it its pedagogical value (there is never education without a form of utopia). Weak thought applied to sport renders it highly educational because:

1. Weak thought changes sports ethics into an authentic and not a fake ethics of tolerance and peace;

2. Weak thought changes sport into a philosophical and critical-pedagogical exercise for all people and in all the phases of life. In fact, weak thought leads us to rethink sport in its structure, showing a way to deconstruct its fundamental and complex meanings, without taking anything for granted, especially in the case of values, of which weak thought reveals not only the relativity but also the complexity (historical and sociocultural) of their structure;

3. Weak thought suggests the development of new forms of creative, experimental, and original alternatives to "play" sport that are pluralistic, intercultural, nondiscriminatory, and respectful of nature, the environment, and differences among people. This third point, as you can imagine, has significant implications from the point of view of pedagogy, school, and sports centers and brings up the possibility of teaching sport as a practical science project in the form of weak thought.

\section{Conclusion: a deconstructed sport}

One can feel free to accept or reject weak thought's opportunity for or "ways" of rethinking sport. Some of them, as we have claimed, may seem to be unattainably utopian, but we do not think so. In any event, just the stress and tension caused by the application of weak thought's principles to sport, and the "deconstruction of the foundations" on which it was built, would have significant implications for education. 
The places where sport is taught (schools and universities as well as community-based sports) are privileged places where these changes can be implemented and these ideas developed.

The application of weak thought to sport suggests the idea of a strong and continued commitment to the individual realization of human values, which it detects, analyzes, and puts into practice in every day (Vattimo, 2010). So we need to educate young people to value "weak sport", teaching them to rethink new possibilities for sport and physical activities and to begin thinking critically about their practice.

This is not only an obligation but a postmodern educator's duty in sport, if we really want sport to develop into a truly human practice respectful of such principles as tolerance and fairness, upon which we like to think the foundation of contemporary ethics in our society is based.

\section{REFERENCES}

D'Agostini, F. (2012). Introduction: The strong reasons for weak thought. In G. Vattimo, The responsibility of the philosopher (pp. 1-36). New York, NY: Columbia University Press.

Isidori, E. (2010). Deconstructing sport: When philosophy and education meet in Derrida's thought. Physical culture and sport. Studies and research, 48(1), 15-20. DOI: 10.2478/v10141-010-0002-4.

Vattimo, G. (1985). The end of modernity: Nihilism and hermeneutics in postmodern cultures. Baltimore, MD: John Hopkins University Press.

Vattimo, G. (1993). The adventure of difference: Philosophy after Nietzsche and Heidegger. Baltimore, MD: John Hopkins University Press.

Vattimo, G. (1994). The transparent society. Baltimore, MD: Johns Hopkins University Press.

Vattimo, G. (1997). Beyond interpretation: The meaning of hermeneutics for philosophy. Stanford, CA: Stanford University Press.

Vattimo, G. (2004). Nihilism and emancipation: Ethics, politics, and law. New York, NY: Columbia University Press.

Vattimo, G. (2010). The responsibility of the philosopher. New York, NY: Columbia University Press.

Vattimo, G., Pier Aldo, R., Carravetta, P. (2012). Weak thought. New York, NY: State University of New York Press.

AUTHOR'S ADDRESS:

Emanuele Isidori

Laboratory of General Pedagogy

University of Rome "Foro Italico"

Piazza L. De Bosis, 15

00135 Roma - Italy

Email: emanuele.isidori@uniroma4.it 